\title{
Survey on Resources of Ephedra Plants in Xinjiang
}

\author{
Changfeng Long, ${ }^{a}$ Nobuko Kakiuchi, ${ }^{*, a}$ Guoyue Zhong, ${ }^{b}$ and Masayuki MikaGE ${ }^{a}$ \\ ${ }^{a}$ Kanazawa University Graduate School of Natural Science and Technology; Kakuma, Kanazawa 920-1192, Japan: and \\ ${ }^{b}$ Chongqing Academy of Chinese Materia Medica; Chongqing, 400065 China. \\ Received August 25, 2004; accepted November 1, 2004
}

\begin{abstract}
The resources of wild Ephedra plants in the Xinjiang Uygur Autonomous Region were surveyed. Ephedra plants mainly grow on the fringes of the Taklimakan Desert and Gureban-tonggute Desert. We found six genotypes of Ephedra przewalskii growing widely in Xinjiang. Three genotypes of Ephedra intermedia were limited to the northern and eastern parts, and Ephedra regeliana scattered in the northern part of Xinjiang. These Ephedra specimens were analyzed for DNA sequences of nuclear ribosomal DNA, internal transcribed spacers 1 and 2 , chloroplastic DNA, trn L intron and $\operatorname{trn} \mathrm{L}-\operatorname{trn} \mathrm{F}$ intergenic spacer. Intraspecific variation of the nucleotide sequence in E. przewalskii was found in different habitats. Norephedrine, ephedrine, pseudoephedrine, and methylephedrine contents of the specimens were determined. Although Ephedra intermedia of all three genotypes contained ephedrine alkaloids, ephedrine alkaloids were not detected in E. regeliana and E. przewalskii.
\end{abstract}

Key words Ephedra; internal transcribed spacer; $\operatorname{trnL}$ intron; $\operatorname{trnL}$-trnF intergenic spacer; ephedrine alkaloid

The herbal drug Mahuang is commonly used in traditional Chinese and Japanese medicines to cure colds. Botanical origin of the drug is confined to Ephedra intermedia SCHRENK et C. A. MEYER, Ephedra sinica STAPF and Ephedra equisetina BUNGE in the pharmacopoeia of both China and Japan. Ephedrine alkaloids, ephedrine, pseudoephedrine, norephedrine, and methylephedrine that are pharmaceutically active the anodyne and antifebrile principles, are abundant in those Ephedra plants. In Mongolia, North America, and some other parts of the world, however, Ephedra species that do not contain ephedrine alkaloids are used traditionally for various diseases. Ephedra przewalskii STAPF, for example, which is reported not to contain any ephedrine alkaloids, is used for stomatitis, nephritis, and inflammation of organs in Mongolian traditional medicine. ${ }^{1)}$ Thus the Ephedra plants that are excluded from the Chinese and Japanese pharmacopoeia are still important for their medicinal usefulness.

To protect Ephedra plant resources and prevent the encroachment of the desert, the Chinese government has banned exports of Mahuang since 1999. Most Mahuang used in Japanese traditional medicine (kampo) is imported from China. Aiming at easing the shortage of Mahuang, we surveyed the resources of Ephedra plants in China. In a previous paper, we reported the results of the survey in the Inner Mongolia Autonomous Region, and Sichuan, Hebei, Shanxi, Gansu, and Qinghai provinces that are known habitats of Ephedra plants. ${ }^{2)}$ We collected specimens of eight Ephedra species, ${ }^{2)}$ and their phylogenetic relationships were studied in DNA sequence analysis of internal transcribed spacers 1 and 2 (ITS1 and -2) and the trnL (UAA) intron and the intergenic spacer between the $\operatorname{trn} \mathrm{L}$ (UAA) 3' exon and the $\operatorname{trn} \mathrm{F}$ (GAA) gene $(\operatorname{trn} \mathrm{L} / \mathrm{F})$ and found that those Ephedra species could be classified into three groups. We developed a simple PCR method for the classification based on the DNA sequence variation between the species in ITS1. ${ }^{3)}$ We found no variation within a species in ITS and $t r n \mathrm{~L} / \mathrm{F}$ in E. przewalskii, $E$. sinica, and E. intermedia.

This time, we surveyed the resources of Ephedra plants in Xinjiang, located on the west of the previous research sites. With a large area including huge deserts and mountains, Xinjiang has varied vegetation from the neighboring provinces on the east, and it continues with variation to the west. We examined whether there is genetic variation in Ephedra plants according to different habitats and tried determine the relationship among morphology, nucleotide sequence, and content of ephedrine alkaloids.

\section{MATERIALS AND METHODS}

Plant Materials Eighteen specimens of three Ephedra species were collected from different habitats in the Xinjiang Uygur Autonomous Region from July 9 through July 23, 2003 (Table 1). All plant specimens were identified by Dr. M. Mikage.

PCR Amplification and Sequencing of Target DNA Regions Total DNA was extracted from the stem of plants with a DNeasy Plant Mini Kit (Qiagen, Germany). Using the total DNA as a template, ITS1, ITS2, and $t r n \mathrm{~L} / \mathrm{F}$ were amplified by PCR as reported previously. ${ }^{3)}$ The amplified PCR product was purified with a QIA quick PCR Purification Kit (Qiagen, Germany). The purified PCR product was subjected to direct sequencing using a Bigdye Terminator Cycle Sequencing Kit (Applied Biosystems) with ABI PRISM 310 (Applied Biosystems).

Analysis of Ephedrine Alkaloids The alkaloid content was determined by the reported method with slight modification. ${ }^{4)}$ The HPLC system is composed of a Shimadzu LC-6A pump, Shimadzu SPD-6A detector, and C-R6A recorder. Five hundred milligrams of powdered Ephedra specimen was extracted with $25 \mathrm{ml}$ of a mixed solvent of $\mathrm{CH}_{3} \mathrm{CN}$ : $\mathrm{H}_{2} \mathrm{O}: \mathrm{H}_{3} \mathrm{PO}_{4}(400: 600: 0.4)$ with $0.4 \%$ SDS by ultrasonic extraction for $30 \mathrm{~min}$. Extracts $(5 \mu \mathrm{l})$ were analyzed with HPLC as followings: column, Devesil ODS-5 Nomura Kagaku (Nagoya, Japan); mobile phase, $\mathrm{CH}_{3} \mathrm{CN}: \mathrm{H}_{2} \mathrm{O}: \mathrm{H}_{3} \mathrm{PO}_{4}$ ( $400: 600: 0.4)$ with $0.4 \% \mathrm{SDS}$; flow rate, $0.8 \mathrm{ml} / \mathrm{min}$; column temperature, $40{ }^{\circ} \mathrm{C}$. Contents of ephedrine, norephedrine, pseudoephedrine, and methylephedrine were calculated from peak areas of UV absorption at $210 \mathrm{~nm}$ by comparing with the standard curve of each compound. 


\section{RESULTS}

Survey of Ephedra Plants in Xinjiang Our survey of Ephedra plants in Xinjiang started in Urumqi on July 9, 2003 and ended in Chongqing on July 30, 2003. The survey route traveled along the northern fringes of the Guerban-tonggute Desert in the Junggar Basin and the southern edge of the Taklimakan Desert in the Tarim Basin through the regions listed in Table 1. Specimens of three Ephedra species, E. intermedia, E. regeliana FLORIN, and E. przewalskii, were collected. We found one specimen, specimen 23-20, that was morphologically identical to E. intermedia collected in
Gansu and Qinghai, with bush-like futures, three scaly leaves, and twisted integument tubes (Fig. 1B). Two specimens, 11-40 and 12-30 (Fig. 1C), showed different morphology from typical E. intermedia. They were smaller in height and had two scaly leaves. Specimens 15-10 and 17-10 had two scaly leaves, but were taller than specimens 11-40 and 12-30. The habitats of E. intermedia were limited to the northern and eastern parts. E. regeliana (Fig. 1D) was scattered in the northern part of Xinjiang. We found E. przewalskii (Fig. 1A) growing widely in Xinjiang. No remarkable morphologic change was detected within the specimens of $E$. przewalskii collected from different habitats.

Table 1. Plant Material Collected in Xinjiang

\begin{tabular}{|c|c|c|c|c|c|c|}
\hline Species & Voucher no. & Locality of voucher & $\begin{array}{l}\text { Date of collection } \\
\text { (r.m.d.) }\end{array}$ & ITS1 & $\begin{array}{c}\text { GenBank accession no. } \\
\text { ITS2 }\end{array}$ & $\operatorname{trn} \mathrm{L} / \mathrm{F}$ \\
\hline \multirow[t]{5}{*}{ E. intermedia } & $11-40$ & Kushui, Qitai xian & 2003.7 .11 & AY730603 & AY394062 & AY423430 \\
\hline & $12-30$ & Aletai Shi & 2003.7 .12 & AY730603 & AY394062 & AY423430 \\
\hline & $15-10$ & Guhe Zhen, Jinghe Xian & 2003.7 .15 & AY730604 & AY394062 & AY423430 \\
\hline & $17-10$ & Kuergan, Kuche Xian & 2003.7 .17 & AY730604 & AY394062 & AY423430 \\
\hline & $23-20$ & Aerjin mountain, Ruoqiang Xian & 2003.7 .23 & AY394070 & AY394062 & AY423430 \\
\hline \multirow[t]{3}{*}{ E. regeliana } & $11-50$ & Saertuohai xiang, Fuyun xian & 2003.7 .11 & AY730602 & AY730607 & AY730599 \\
\hline & $12-20$ & Beitun Zhen, Aletai Shi & 2003.7 .12 & AY730602 & AY730607 & AY730599 \\
\hline & $13-10$ & Heishitou, Aletai Shi & 2003.7 .13 & AY730602 & AY730607 & AY730599 \\
\hline \multirow[t]{10}{*}{ E. przewalskii } & 303 & Hami Shi & 2003.7 .9 & AY394072 & AY394064 & AY423432 \\
\hline & 306 & Urumqi Shi & 2003.7 .9 & AY394072 & AY730606 & AY423432 \\
\hline & $11-10$ & Hongliugou, Qitai xian & 2003.7 .11 & AY394072 & AY730605 & AY423432 \\
\hline & $11-31$ & Hongliugou, Qitai xian & 2003.7 .11 & AY730601 & AY730606 & AY423432 \\
\hline & $13-40$ & Wuerhe Xiang, Kelamayi Shi & 2003.7 .13 & AY730601 & AY730606 & AY730598 \\
\hline & $15-20$ & Daheyanzi, Jinghe Xian & 2003.7 .15 & AY730601 & AY730606 & AY730598 \\
\hline & $19-10$ & Qilang Xiang, Keping Xian & 2003.7.19 & AY730601 & AY730606 & AY423432 \\
\hline & $20-10$ & Mukuilai, Pishan Xian & 2003.7 .20 & AY730601 & AY730606 & AY730600 \\
\hline & $21-10$ & Aoyitogelake Xiang, Yutian Xian & 2003.7 .21 & AY730601 & AY730606 & AY730600 \\
\hline & $22-10$ & Longkou, Qiemo Xian & 2003.7 .22 & AY730601 & AY730606 & AY730600 \\
\hline
\end{tabular}

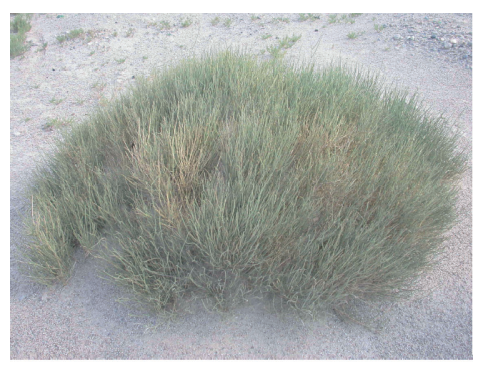

A

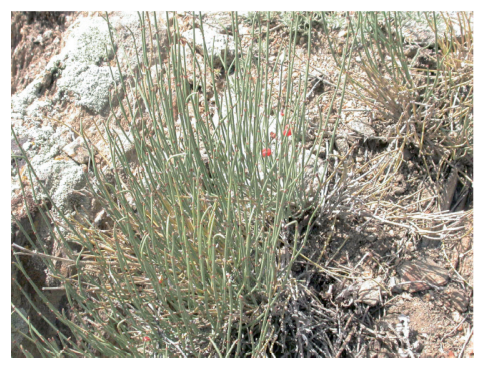

$\mathrm{C}$

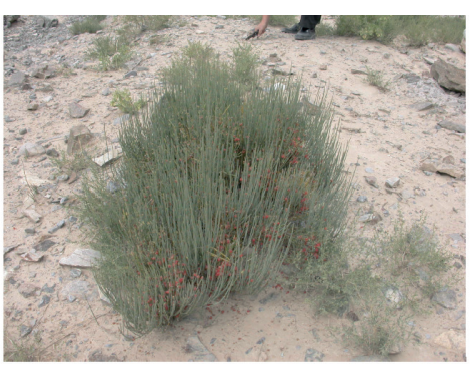

B

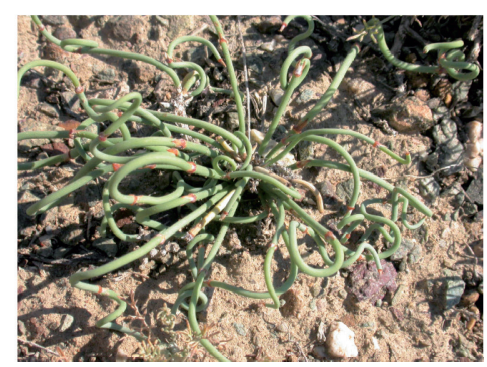

$\mathrm{D}$

Fig. 1. Photos of Ephedra Plants Collected in Xinjiang

A, E. przewalskii (11-31); B, E. intermedia (23-20); C, E. intermedia (12-30); D, E. regeliana (11-50). 
Table 2. Variation in DNA Sequences in ITS1, ITS2, and trnL/F of Ephedra Plants Collected in Xinjiang

\begin{tabular}{|c|c|c|c|c|c|c|c|c|c|c|c|}
\hline \multirow{2}{*}{ Species } & \multirow{2}{*}{ Genotype } & \multirow{2}{*}{ Voucher no. } & \multicolumn{6}{|c|}{ ITS1 } & \multirow{2}{*}{$\begin{array}{c}\text { ITS2 } \\
205\end{array}$} & \multicolumn{2}{|c|}{$\operatorname{trn} \mathrm{L} / \mathrm{F}$} \\
\hline & & & 179 & 773 & 884 & 910 & 1004 & 1119 & & 96 & 398 \\
\hline \multirow[t]{3}{*}{ E. intermedia } & Ei-I & $23-20$ & $\mathrm{~T}$ & $\mathrm{~T}$ & A & A & $\mathrm{C}$ & A & G & $\mathrm{C}$ & A \\
\hline & Ei-II & $15-10,17-10$ & $\mathrm{~T}$ & $\mathrm{C}$ & A & $\mathrm{C}$ & $\mathrm{C}$ & G & G & $\mathrm{C}$ & A \\
\hline & Ei-III & $11-40,12-30$ & $\mathrm{~T}$ & $\mathrm{C}$ & $\mathrm{A}$ & $\mathrm{C}$ & $\mathrm{T}$ & $\mathrm{R}(\mathrm{A}, \mathrm{G})$ & $\mathrm{G}$ & $\mathrm{C}$ & $\mathrm{A}$ \\
\hline E. regeliana & $\mathrm{Er}$ & $11-50,12-20,13-10$ & $\mathrm{~T}$ & $\mathrm{C}$ & A & $\mathrm{C}$ & $\mathrm{C}$ & $\mathrm{R}(\mathrm{A}, \mathrm{G})$ & G & $\mathrm{C}$ & $\mathrm{C}$ \\
\hline \multirow[t]{6}{*}{ E. przewalskii } & Ep-I & 303 & $\mathrm{C}$ & $\mathrm{C}$ & $\mathrm{C}$ & $\mathrm{C}$ & $\mathrm{C}$ & G & A & $\mathrm{C}$ & A \\
\hline & Ep-II & $11-10$ & $\mathrm{C}$ & $\mathrm{C}$ & $\mathrm{C}$ & $\mathrm{C}$ & $\mathrm{C}$ & G & $\mathrm{R}(\mathrm{A}, \mathrm{G})$ & $\mathrm{C}$ & A \\
\hline & Ep-III & 306 & $\mathrm{C}$ & $\mathrm{C}$ & $\mathrm{C}$ & $\mathrm{C}$ & $\mathrm{C}$ & G & G & $\mathrm{C}$ & A \\
\hline & Ep-IV & $11-31,19-10$ & $\mathrm{~T}$ & $\mathrm{C}$ & $\mathrm{C}$ & $\mathrm{C}$ & $\mathrm{C}$ & G & G & $\mathrm{C}$ & A \\
\hline & Ep-V & $13-40,15-20$ & $\mathrm{~T}$ & $\mathrm{C}$ & $\mathrm{C}$ & $\mathrm{C}$ & $\mathrm{C}$ & $\mathrm{G}$ & $\mathrm{G}$ & $\mathrm{C}$ & $\mathrm{C}$ \\
\hline & Ep-VI & $20-10,21-10,22-10$ & $\mathrm{~T}$ & $\mathrm{C}$ & $\mathrm{C}$ & $\mathrm{C}$ & $\mathrm{C}$ & G & G & $\mathrm{T}$ & A \\
\hline
\end{tabular}

Nucleotide numbers were counted from the beginning of the respective regions.

Table 3. Content of Four Ephedrine Alkaloids, Norephedrine (NE), Pseudoephedrine (PE), Ephedrine (E), and Methylephedrine (ME), in Aerial Parts of Ephedra Plants Collected in Xinjiang

\begin{tabular}{|c|c|c|c|c|c|c|c|}
\hline \multirow{2}{*}{ Species } & & \multirow{2}{*}{ Plant no. } & \multicolumn{5}{|c|}{ Content ( $\%$ of dry weight) } \\
\hline & & & NE & $\mathrm{PE}$ & $\mathrm{E}$ & ME & $\mathrm{NP}+\mathrm{EP}+\mathrm{P}$ \\
\hline \multirow{5}{*}{ E. intermedia } & Ei-I & $23-20$ & 0.009 & 1.56 & ND & ND & 1.57 \\
\hline & Ei-II & $15-10$ & 0.048 & 0.71 & 0.33 & ND & 1.09 \\
\hline & & $17-10$ & 0.031 & 1.54 & 0.24 & ND & 1.81 \\
\hline & Ei-III & $11-40$ & 0.011 & 1.42 & 0.031 & ND & 1.46 \\
\hline & & $12-30$ & 0.088 & 0.15 & 0.22 & ND & 0.46 \\
\hline E. przewalskii & & All specimens & $\mathrm{ND}$ & ND & ND & ND & \\
\hline E. regeliana & & All specimens & ND & ND & ND & ND & \\
\hline
\end{tabular}

ND, not detected.

Nucleotide Variation in ITS1, ITS2, and $\operatorname{trn} \mathrm{L} / \mathrm{F}$ The results of DNA analysis of ITS1, ITS2, and $\operatorname{trn} \mathrm{L} / \mathrm{F}$ are shown in Table 2. The nucleotide numbers of respective regions were found to be $1139 \mathrm{bp}$ for ITS1, $246 \mathrm{bp}$ for ITS2, and $465 \mathrm{bp}$ for $t r n \mathrm{~L} / \mathrm{F}$.

In E. intermedia, we found three genomic variations, which were correlated with morphologic change. One specimen, 23-20 (genotype Ei-I), which was collected in the eastern part, showed an identical sequence as in the previous report. The other four specimens with two morphologic types had substitutions at positions 773 and 910 in ITS1 compared with 23-20. Specimens 11-40 and 12-30 (genotype Ei-III) had an additional substitution at position 1004 and an ambiguity of adenine/guanine at 1119 , where specimens $15-10$ and 17-10 (genotype Ei-II) had guanine.

In contrast to three specimens of E. przewalskii collected in Gansu and Qinghai, which had identical sequences, six genotypes were found in Xinjiang. Specimen 303 (genotype Ep-I) showed the same sequences as that of E. przewalskii in Gansu and Qinghai. Ep-I, -II, and -III, which had the same sequences in ITS1 and $\operatorname{trn} \mathrm{L} / \mathrm{F}$, showed variation in ITS2. Specimen 11-10 showed almost equal intensity of adenine and guanine signals at position 205 in ITS2. The other specimens of E. przewalskii had substitutions at position 205 from adenine of genotype Ep-I to guanine. Ep-IV, Ep-V and Ep-VI were identical in ITS1 and -2 , but not in $\operatorname{trn} \mathrm{L} / \mathrm{F}$. The specimens of genotype $\mathrm{Ep}-\mathrm{V}$ had identical $\operatorname{trn} \mathrm{L} / \mathrm{F}$ sequences to those of E. regeliana. The specimens of genotype Ep-VI col- lected in the south of the Taklimakan Desert had substitutions from the cytosine of genotype Ep-I to thymine at position 96 of $\operatorname{trn} \mathrm{L} / \mathrm{F}$.

Three specimens of E. regeliana had the same nucleotide sequences, including an ambiguity of adenine/guanine at position 1119 in ITS1.

Ephedrine Alkaloid Content The specimens of E. intermedia contained ephedrine alkaloids (Table 3), although variation in content was observed. The total content of ephedrine alkaloids varied from $0.46 \%$ to $1.81 \%$. On the other hand, although it seems that huge gaps between the habitats resulted in intraspecific variation in DNA sequences, no specimen of $E$. przewalskii contained detectable amounts of ephedrine alkaloids, and neither did the E. regeliana specimens.

\section{DISCUSSION}

Desert covers the most of Xinjiang. It is divided into two parts by Tianshan Mountains, the Gureban-tonggute Desert and Jungger Basin in the north, and the Taklimakan Desert and Tarim Basin in the south. Vegetation in the peripheral areas of the desert consists of thin scrub and dwarf woodlands dominated by representative desert plants such as saxoul (Haloxylon ammodendron) and E. przewalskii.

Many studies reported that there was intraspecific variation in $\operatorname{trn} \mathrm{L} / \mathrm{F}$ according to geographic change. ${ }^{5-7)}$ In our survey, we found $E$. przewalskii had intraspecific variation in 


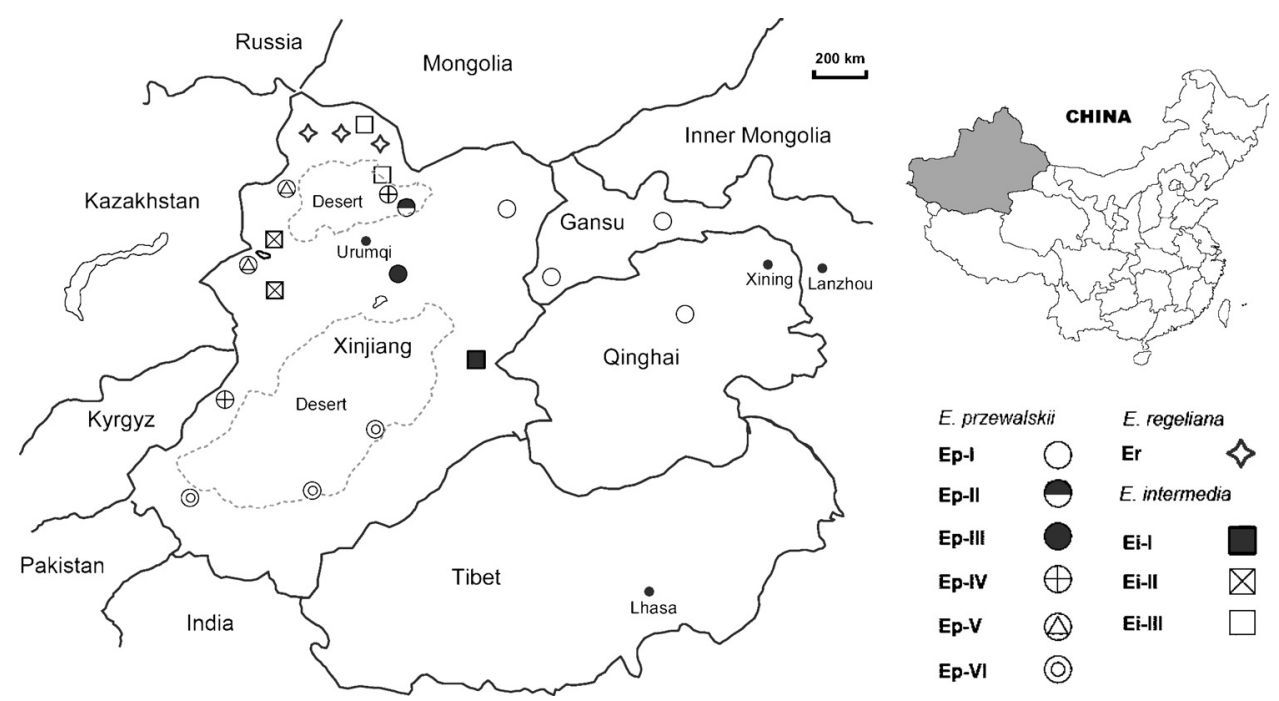

Fig. 2. Collection Sites of Ephedra Plants in Xinjiang

ITS1, ITS2, and $\operatorname{trn} \mathrm{L} / \mathrm{F}$ and there was a close relationship between genomic variation and habitat location. Only specimen 303 , which was collected near the border of Gansu and Xinjiang, has the same sequences as specimens collected in Gansu and Qinghai. The habitats of specimens belonging to the same genotype were near each other except for that of genotype Ep-IV. We found specimens with genotype Ep-I, Ep-II, Ep-III, Ep-IV, and Ep-V in the north, and genotype Ep-IV and Ep-VI in the south part. Proceeding along northern or southern edge of the deserts from east to west, DNA sequences of the specimens of E. przewalskii continuously changed. Geographic factors may thus affect DNA sequences.

E. regeliana grows in the northern part of Xinjiang. E. regeliana had DNA sequences similar to E. przewalskii genotype Ep-V, whose habitat is also located in the northern part. Interestingly, there were no detectable amounts of ephedrine alkaloids in E. regeliana, although there was a report that E. regeliana collected from Pakistan contained ephedrine and pseudoephedrine. ${ }^{8)}$ There may be a close relationship between E. regeliana and E. przewalskii, although this conclusion can not be deduced from the morphology.

Three genotypes of E. intermedia were different morphologically as well as genetically. In spite of morphologic and genetic variations, they all showed high contents of ephedrine alkaloids. Furthermore, except for specimen 1230 , they contained more pseudoephedrine than ephedrine, which is characteristic of E. intermedia. ${ }^{9)}$

From the survey of Ephedra plants in Xinjiang, we con- clude that medically useful Ephedra plants are still abundant, and that they show variations compared with those from the other eastern regions in China.

Acknowledgments We are grateful to Mr. S.Y. Qin and Mr. Z.B. Yu of the Chongqing Academy of Chinese Materia Medica for help during the survey in Xinjiang. We also thank Professor S.Q. Cai for advices and Ms. Y. Ushida for technical help in the HPLC analysis of ephedrine alkaloids. This work was supported by Grant-in-Aid for the 21st Century COE Program from the Ministry of Education, Culture, Sports, Science and Technology, Japan.

\section{REFERENCES}

1) Takano F., Yoshizaki F., Fushiya S., Hayasaka H., Ohba K., Batkhuu J., Sanchir C., Boldsaikhan B., Kampo Med., 54, 963-972 (2003).

2) Mikage M., Takahashi A., Chen H. B., Li Q. S., Nat. Med., 57, $202-$ 208 (2003).

3) Long C. F., Kakiuchi N., Takahashi A., Komatsu K., Cai S. Q., Makage M., Planta Med., 70, 1080-1084 (2004).

4) Kondo N., Mikage M., Idaka K., Nat. Med., 53, 194-200 (1999).

5) Aoki K., Suzuki T., Murakami N., J. Plant Res., 116, 337-344 (2003).

6) Fujii N., Tomaru N., Okuyama K., Koike T., Mikami T., Ueda K., Plant Syst. Evol., 232, 21-33 (2002).

7) Ohi T., Wakabayashi M., Wu S. G., Murata J., J. Jpn. Bot., 78, 1-14 (2003).

8) Caveney S., Charlet D. A., Freitag H., Maier-Stolte M., Starratt A. N., Am. J. Bot., 88, 1199-1208 (2001).

9) Zhang J. S., Tian Z., Lou Z. C., Yao Xие Xие Bao, 24, 865-871 (1989). 